\title{
Comparison of Polyfluoroalkyl Compound Concentrations in Maternal Serum and Amniotic Fluid: A Pilot Study
}

\author{
Cheryl R. Stein ${ }^{\mathrm{a}}$, Mary S. Wolffa ${ }^{\mathrm{a}}$ Antonia M. Calafat ${ }^{\mathrm{b}}$, Kayoko Kato ${ }^{\mathrm{b}}$, and Stephanie M. \\ Engel ${ }^{C}$ \\ Cheryl R. Stein: cheryl.stein@mssm.edu; Mary S. Wolff: mary.wolff@mssm.edu; Antonia M. Calafat: acalafat@cdc.gov; \\ Kayoko Kato: kkato1@cdc.gov; Stephanie M. Engel: stephanie.engel@unc.edu \\ aDepartment of Preventive Medicine, Mount Sinai School of Medicine, One Gustave L. Levy \\ Place, Box 1057, New York, NY 10029-6574 \\ bDivision of Laboratory Sciences, National Center for Environmental Health, Centers for Disease \\ Control and Prevention, Atlanta, GA 30341 \\ 'Department of Epidemiology, Gillings School of Global Public Health, University of North \\ Carolina, Chapel Hill, 2104C McGavran-Greenberg, CB\#7435, Chapel Hill, NC 27599-7435
}

\section{Abstract}

The extent to which polyfluoroalkyl compounds (PFCs) are detectable in amniotic fluid is unknown. Using paired samples from 28 women, we compared the concentration of 8 PFCs measured in serum, the standard matrix for assessing human exposure, amniotic fluid from routine amniocentesis, and urine. Perfluorooctanoate (PFOA), perfluorononanoate (PFNA), perfluorooctane sulfonate (PFOS), and perfluorohexane sulfonate (PFHxS) were detected in all maternal serum samples. The number of amniotic fluid samples with detectable concentrations differed by PFC (PFOA $n=24$; PFNA $n=10$; PFOS $n=9$; PFHxS $n=4)$. The correlation coefficient between maternal serum and amniotic PFC levels varied considerably by PFC (PFOA $\rho=0.64$, $\mathrm{p}<0.001$; PFNA $\rho=0.05, \mathrm{p}=0.9$; PFOS $\rho=0.76, \mathrm{p}=0.01$; PFHxS $\rho=0.80, \mathrm{p}=0.2$ ). Using linear regression, PFOA appeared to be commonly detected in amniotic fluid if the serum concentration exceeded approximately $1.5 \mathrm{ng} / \mathrm{mL}$ whereas PFOS was rarely detected in amniotic fluid until the serum concentration was about $5.5 \mathrm{ng} / \mathrm{mL}$. No PFCs were detected in urine.

\section{Keywords}

amniotic fluid; fluorocarbons; maternal serum; perfluorooctanoate; perfluorooctane sulfonate; pregnancy

\section{Introduction}

Perfluorooctanoate (PFOA) is a synthetic chemical that has been used in the manufacture of fluoropolymers since the 1950s [1], and may also result from the breakdown of a related

(C) 2012 Elsevier Inc. All rights reserved.

CORRESPONDING AUTHOR: Cheryl R. Stein, Ph.D., Assistant Professor, Department of Preventive Medicine, Mount Sinai School of Medicine, One Gustave L. Levy Place, Box 1057, New York, NY 10029-6574, Phone: 212-824-7083, Fax: 212-996-0407, cheryl.stein@mssm.edu.

Publisher's Disclaimer: This is a PDF file of an unedited manuscript that has been accepted for publication. As a service to our customers we are providing this early version of the manuscript. The manuscript will undergo copyediting, typesetting, and review of the resulting proof before it is published in its final citable form. Please note that during the production process errors may be discovered which could affect the content, and all legal disclaimers that apply to the journal pertain. 
group of chemicals called fluorinated telomers (alcohols and related compounds) [2]. Fluoropolymers are used in almost all industry segments, including aerospace; automotive; building/construction; chemical processing; electrical and electronics; semiconductor; and textile [2]. Telomers are used as surfactants and as surface treatment chemicals in many products, including firefighting foams; personal care and cleaning products; and oil, stain, grease, and water repellent coatings on carpet, textiles, leather, and paper [2]. Human exposure to PFCs typically occurs through transfer from food packaging and preparation materials and bioaccumulation in the food chain, as well as exposure to household dust [3].

PFOA and other polyfluoroalkyl compounds (PFCs) with comparable industrial uses perfluorooctane sulfonate (PFOS), perfluorohexane sulfonate (PFHxS), perfluorononanoate (PFNA) - are persistent organic pollutants that have been detected worldwide in both wildlife and humans, with higher exposure closer to urbanized and industrialized regions [4]. In the United States (U.S.) general population, PFOA, PFOS, and PFHxS were detected in the serum of all participants from the 1999 - 2000 National Health and Nutrition Examination Survey (NHANES); PFNA was detected in 95\% of participants [5]. In NHANES 2003 - 2004, there were minor reductions in the percent of samples with detectable concentrations of PFOA, PFOS, and PFHxS, and the geometric mean concentrations for these three compounds dropped slightly [6]. For PFNA, however, in addition to an increase in the percent of serum samples with detectable concentrations to $98.8 \%$, the geometric mean doubled to $1.0 \mathrm{ng} / \mathrm{mL}$ between NHANES cycles. In the $2005-$ 2006 and 2007 - 2008 NHANES surveys, the percent of samples with detectable concentrations of these chemicals remained stable, although the concentrations increased slightly for all but PFOS [7]. In the 2007 - 2008 NHANES, the geometric mean (95\% confidence interval (CI)) concentration of these chemicals in females aged 12 years or older was $3.56 \mathrm{ng} / \mathrm{mL}$ (3.38-3.74) for PFOA; $10.70 \mathrm{ng} / \mathrm{mL}$ (9.72-11.8) for PFOS; $1.46 \mathrm{ng} / \mathrm{mL}$ (1.30-1.64) for PFHxS; and $1.33 \mathrm{ng} / \mathrm{mL}(1.20-1.47)$ for PFNA [7]. The serum elimination half-life is estimated at 2.3 [8] to 4 [9] years for PFOA, 5 years for PFOS [9], and 8.5 years for PFHxS [9]. A half-life estimate is not available for PFNA.

Toxicology studies highlight the potential for PFCs to affect fetal growth and development (reviewed in [10-12]). Rat pups prenatally exposed to PFOS show delayed behavioral milestones [13], and delayed task learning has been noted in female mouse pups prenatally exposed to PFOS and maternal restraint [14]. The limited developmental toxicology literature suggests possible adverse effects of PFOA and PFOS on fetal growth and viability and postnatal growth $[11,15]$.

Several epidemiologic studies have evaluated the association between PFCs and reproductive health [16-19]. These recently reviewed studies suggest small, inconsistent decrements in birth weight in relation to maternal PFOA and PFOS exposure [12]. No associations have been observed with gestational age, examined either continuously [16, 20] or dichotomized as birth less than 37 completed weeks gestation [17, 20]. Studies of other indications of fetal growth, such as head and abdominal circumference, birth length, and ponderal index, have yielded equivocal results $[16,18,19]$. Among a subset of women exposed to higher than background levels of PFOA through contaminated drinking water but typical levels of PFOS, there were modest associations of PFOA with preeclampsia [21, 22] and of PFOS with preeclampsia and low birthweight [22].

PFOA and PFOS have been detected in amniotic fluid from mouse and rat models [23, 24]. In humans, PFCs have been detected in matched maternal prenatal blood, umbilical cord blood, breast milk, and infant blood samples [25-30]. Several PFCs have been detected across all matrices. The maternal:cord blood as well as the maternal blood:breast milk transfer ratios are greater for PFOA than for PFOS. A recent study describes the detection of 
PFOS in 300 stored human amniotic fluid samples from amniocenteses occurring in 1980 to 1996 [31]. We tested amniotic fluid for PFCs, and compared the concentrations measured in paired maternal serum and amniotic fluid samples. We also tested maternal urine for PFCs, although urine is rarely used for PFC biomonitoring in humans.

\section{Materials and Methods}

The Study of Advanced Reproductive Age and Environmental Health (SARAEH) was a prospective pregnancy cohort designed to assess toxicant exposures among women undergoing amniocentesis for an indication of advanced maternal age. SARAEH enrolled 97 pregnant women from $2005-2008$ who were receiving amniocentesis and planning to deliver at the Mount Sinai Medical Center in New York, NY. Amniotic fluid supernatant that would normally have been discarded after completion of clinical care investigations was retained for this study. Spot urine samples were collected from women on the same day as their amniocentesis appointment and were immediately aliquoted and stored at $-80^{\circ} \mathrm{C}$. Peripheral blood samples were collected during routine prenatal care venipuncture, although blood samples were available only for 42 women (43\%). Blood samples were generally collected at prenatal care visits several weeks after amniotic fluid and urine collection. There were no statistically significant differences in maternal demographics (maternal age, race/ ethnicity, marital status, education) or pregnancy characteristics (gestational age at enrollment, parity, pre-pregnancy body mass index (BMI), pregnancy weight gain) between the women with and without blood samples. From this group of 42 women with both amniotic fluid and serum samples, we randomly selected 28 (67\%) for study inclusion.

Fresh amniotic fluid was delivered to the Mount Sinai Human Medical Genetics laboratory for processing following collection for clinical analyses. Amniotic fluid was centrifuged and cells were separated for clinical care purposes, along with a small amount of supernatant. Residual amniotic fluid supernatant was stored in plastic containers at $-20^{\circ} \mathrm{C}$ for one month before being released for research purposes. Once released for research, amniotic fluid was obtained by study personnel and aliquoted into $2 \mathrm{~mL}$ polypropylene cyrovials for storage at $-80^{\circ} \mathrm{C}$. Paired amniotic fluid, serum, and urine samples collected from the same woman were shipped to the U.S. Centers for Disease Control and Prevention (CDC) for laboratory analysis. Institutional Review Board approval for this study was granted from the Mount Sinai Program for the Protection of Human Subjects. The involvement of the CDC laboratory was determined not to constitute engagement in human subject research.

We measured perfluorooctane sulfonamide (PFOSA), 2-(N-ethyl-perfluorooctane sulfonamido) acetate (Et-PFOSA-AcOH), 2-(N-methyl-perfluorooctane sulfonamido) acetate (Me-PFOSA-AcOH), PFHxS, PFOS, PFOA, PFNA, and perfluorodecanoate (PFDeA) in serum, urine, and amniotic fluid using a modification of the online solid-phase extraction (SPE) coupled to reversed-phase high-performance liquid chromatographytandem mass spectrometry approach previously described [32]. We used ${ }^{13} \mathrm{C}_{2}$-PFOA, ${ }^{18} \mathrm{O}_{2^{-}}$ PFOS, ${ }^{18} \mathrm{O}_{2}$-PFOSA, ${ }^{13} \mathrm{C}_{5}$-PFNA, ${ }^{13} \mathrm{C}_{2}$-PFDeA, $\mathrm{D}_{3}$-Me-PFOSA-AcOH, D -Et-PFOSA$\mathrm{AcOH}$ and ${ }^{18} \mathrm{O}_{2}$-PFHxS as internal standards. Limits of detection (LODs), calculated as $3 \mathrm{~S}_{0}$, where $S_{0}$ is the standard deviation as the concentration approaches zero, ranged from $0.1 \mathrm{ng} /$ $\mathrm{mL}$ to $0.2 \mathrm{ng} / \mathrm{mL}$. Low-concentration $(\sim 2 \mathrm{ng} / \mathrm{mL}-\sim 10 \mathrm{ng} / \mathrm{mL})$ and high-concentration $(\sim 5$ $\mathrm{ng} / \mathrm{mL}-\sim 25 \mathrm{ng} / \mathrm{mL}$ ) quality-control (QC) materials were analyzed with blanks, analytical standards and study samples. The QC concentrations were evaluated using standard statistical probability rules.

Statistical analysis was performed using SAS version 9.2 (Cary, NC) and Stata version 10 (College Station, TX). We examined the relation between PFC concentrations measured in paired maternal serum and amniotic fluid samples using the Spearman correlation 
coefficient. Correlation coefficients were calculated only among the samples where the concentration was above the LOD for both amniotic fluid and serum. We also used graphical techniques to visualize the paired concentration distributions. In some graphical depictions concentrations below the LOD were plotted at the LOD divided by the square root of 2 . Lastly, we used independent group T-tests to examine whether detection of PFCs in amniotic fluid varied by maternal age at amniocentesis, gestational age at amniocentesis, or pre-pregnancy body mass index (BMI).

\section{Results}

Women were enrolled in their second trimester (mean 17.4 weeks; standard deviation (SD) 2.0; range $15-23$ ) at a mean maternal age of 34.8 (SD 5.1) years (Table 1). On average 6.8 (SD 5.5) weeks elapsed between collection of amniotic fluid and serum samples. The majority of women (53.8\%) were pregnant for at least the third time.

Six of eight PFCs tested were detected in maternal prenatal serum, five of eight PFCs tested were detected in amniotic fluid, and no PFCs tested were detected in maternal prenatal urine (Table 2). We detected PFHxS, PFOS, PFOA, and PFNA in all of the serum samples; two other PFCs were detected less frequently (Me-PFOSA-AcOH, 64\% and PFDeA, 89\%). We did not detect PFOSA or Et-PFOSA-AcOH in any of the serum or amniotic fluid samples. Detection of PFCs in amniotic fluid did not vary by parity or pre-pregnancy BMI (data not shown). Detection did vary by maternal age $(\mathrm{p}=0.03)$ and gestational age $(\mathrm{p}<0.001)$ for PFOA only. Both the concentrations and the frequency of detection of all PFCs in amniotic fluid were lower than in serum. The median concentrations in amniotic fluid were around the limit of quantification ( $3 * \mathrm{LOD})$ of the analytical method. The Spearman correlation coefficient, a measure of rank order used to compare the paired serum and amniotic fluid concentrations, varied considerably by PFC (PFOA $\rho=0.64$, $p<0.001$; PFNA $\rho=0.05, p=0.9$; PFOS $\rho=0.76, p=0.01 ;$ PFHxS $\rho=0.80, p=0.2$ ). The sulfonates (PFHxS and PFOS), although detected less frequently in amniotic fluid than the carboxylates (PFOA and PFNA), showed stronger correlations between serum and amniotic fluid. The medians of the ratios of maternal serum:amniotic fluid concentrations were 12.8:1 for PFOA and 25.5:1 for PFOS. Based on simple regression (Figures 1A, 1B), PFOA was commonly detected in amniotic fluid once the serum concentration reached approximately $1.5 \mathrm{ng} / \mathrm{mL}$, whereas PFOS was rarely detected in amniotic fluid until the serum concentration reached at least $5.5 \mathrm{ng} / \mathrm{mL}$.

\section{Discussion}

We detected PFCs in amniotic fluid at concentrations approximately 10 to 20 -fold lower than in maternal serum. We did not detect PFCs in urine. Maternal prenatal serum concentrations in this small number of New York City pregnant women are comparable to national averages from NHANES 2005 - 2006 and 2007 - 2008. In our study, the highest PFC concentrations in serum were PFOA and PFOS, and these compounds were among the most frequently detected PFCs in amniotic fluid.

Amniotic fluid concentrations of the PFCs we detected were lower than those reported by Jensen et al [31] and considerably lower than cord blood concentrations noted in previous studies [25-30]. In general, maternal blood concentrations are about 1 to 2-fold higher than paired cord blood concentrations, and maternal:cord blood ratios are lower for PFOA $(\sim 1.3: 1)$ than PFOS ( 3.0:1) [33]. The maternal serum:amniotic fluid ratios we observed replicated this doubled proportionality between the PFOA and PFOS materal:cord blood ratios. A lower maternal:cord blood ratio indicates that PFOA is more readily transferred to the fetus than PFOS. Consequently, the fetus may have a greater body burden of PFOA that can be partitioned into amniotic fluid from fetal tissue. Alternatively, we may have detected 
PFOA in amniotic fluid more frequently than PFOS because the limit of detection for PFOS was twice as high.

Amniotic fluid is an aqueous solution with suspended desquamated fetal epithelial cells [34]. As gestation progresses, other organic material including fetal feces and urine are also present. The fluid contains approximately equal parts organics (proteins, carbohydrates, fats, enzymes, hormones, pigments) and inorganics. In human sera, PFCs associate with circulating proteins [35]. It is possible that some PFCs were removed from the amniotic fluid during its initial processing for clinical care purposes when the fluid was centrifuged and the precipitated cells retained for genetic testing. If the individual PFCs have differential protein binding preferences, they may have been differentially removed from the fluid supernatant available for this investigation. This potential reduction in PFC concentration would have limited our ability to detect the compounds as well as impacting the concentrations we measured.

In the amniotic fluid samples in this study, PFOA appeared to be more soluble than PFOS because it was detected in amniotic fluid at lower maternal serum levels than PFOS (Figures 1A, 1B). These findings are consistent with the relative solubility of PFCs in water (PFOA: $3400 \mathrm{mg} / \mathrm{L}$; PFOS: $570 \mathrm{mg} / \mathrm{L}$ ). Solubility may also partially explain the lower PFOA maternal:cord blood ratio because cord serum is more polar than maternal serum [36]. In addition to differential solubility, protein binding across matrices, carbon chain length, and the charged functional moiety of the compound, such as the carboxylate in PFOA and PFNA compared with the sulfonate in PFOS and PFHxS, may account for some of the variation in concentrations of PFCs we observed in amniotic fluid [37].

Based on this and other studies, the relative concentrations of PFOA and PFOS in maternal serum, cord serum, amniotic fluid, and urine are approximately 100:50:5:0.1. In a Japanese study, the ratio of PFOA and PFOS in serum as compared to urine was approximately 1000:1 [38]. This ratio is consistent with the undetectable levels we found in urine because our LOD ranged from $0.1-0.2 \mathrm{ng} / \mathrm{mL}$ as compared to the $0.001 \mathrm{ng} / \mathrm{mL}$ reported in the Japanese study.

While we cannot rule out the possibility of external contamination because the amniotic fluid samples had been processed previously, the detection of PFCs in amniotic fluid suggests that in addition to blood borne in utero exposure [16, 25-30] the fetus is also ingesting and bathing in low levels of some PFCs.

Several PFCs are persistent organic pollutants under the Stockholm Convention. These chemicals have long elimination half-lives (e.g., years) and some of them can accumulate and biomagnify in the food chain. Animal studies show hepatoxicity, developmental toxicity, immunotoxicity, hormonal effects, and carcinogenic potency. Studies of potential human health effects are ongoing. The detection of several PFCs in amniotic fluid calls for replication of these findings, including examination by maternal age, parity, inter-pregnancy interval, and gestational age at amniotic fluid collection. This study increases the urgency to identify any potential reproductive and development toxicity of these compounds.

\section{Acknowledgments}

This study was supported by the National Institute of Environmental Health Sciences (R21ES014034; K01 ES019156). The authors thank Rebecca Bausell, Molly Meadows, Brian Basden, Carmen Dunbar, and Tao Jia for technical assistance. The authors have no competing financial interests to declare. The findings and conclusions in this work are those of the authors and do not necessarily represent the views of the Centers for Disease Control and Prevention. 


\section{ABBREVIATIONS}

$\begin{array}{ll}\text { NHANES } & \text { National Health and Nutrition Examination Survey } \\ \text { PFC } & \text { polyfluoroalkyl compound } \\ \text { PFHxS } & \text { perfluorohexane sulfonate } \\ \text { PFNA } & \text { perfluorononanoate } \\ \text { PFOS } & \text { perfluorooctane sulfonate } \\ \text { PFOA } & \text { perfluorooctanoate } \\ \text { SD } & \text { standard deviation } \\ \text { US } & \text { United States }\end{array}$

\section{References}

1. Perfluorooctanoic Acid (PFOA). Washington, DC: U.S. Environmental Protection Agency; 2009.

2. Perfluorooctanoic Acid (PFOA) and Fluorinated Telomers. Washington, DC: U.S. Environmental Protection Agency; 2009.

3. D'Eon JC, Mabury SA. Is Indirect Exposure a Significant Contributor to the Burden of Perfluorinated Acids Observed in Humans? Environ Sci Technol. 2011; 45:7974-84. [PubMed: 21630688]

4. Houde M, Martin JW, Letcher RJ, Solomon KR, Muir DC. Biological monitoring of polyfluoroalkyl substances: A review. Environ Sci Technol. 2006; 40:3463-73. [PubMed: 16786681]

5. Calafat AM, Kuklenyik Z, Reidy JA, Caudill SP, Tully JS, Needham LL. Serum concentrations of 11 polyfluoroalkyl compounds in the u.s. population: data from the national health and nutrition examination survey (NHANES). Environ Sci Technol. 2007; 41:2237-42. [PubMed: 17438769]

6. Calafat AM, Wong LY, Kuklenyik Z, Reidy JA, Needham LL. Polyfluoroalkyl chemicals in the U.S. population: data from the National Health and Nutrition Examination Survey (NHANES) 2003-2004 and comparisons with NHANES 1999-2000. Environ Health Perspect. 2007; 115:1596602. [PubMed: 18007991]

7. Kato K, Wong LY, Jia LT, Kuklenyik Z, Calafat AM. Trends in Exposure to Polyfluoroalkyl Chemicals in the U.S. Population: 1999-2008 (dagger). Environ Sci Technol. 2011

8. Bartell SM, Calafat AM, Lyu C, Kato K, Ryan PB, Steenland K. Rate of decline in serum PFOA concentrations after granular activated carbon filtration at two public water systems in Ohio and West Virginia. Environ Health Perspect. 2010; 118:222-8. [PubMed: 20123620]

9. Olsen GW, Burris JM, Ehresman DJ, Froehlich JW, Seacat AM, Butenhoff JL, et al. Half-life of serum elimination of perfluorooctanesulfonate, perfluorohexanesulfonate, and perfluorooctanoate in retired fluorochemical production workers. Environ Health Perspect. 2007; 115:1298-305. [PubMed: 17805419]

10. Lau C, Anitole K, Hodes C, Lai D, Pfahles-Hutchens A, Seed J. Perfluoroalkyl acids: a review of monitoring and toxicological findings. Toxicol Sci. 2007; 99:366-94. [PubMed: 17519394]

11. Lau C, Butenhoff JL, Rogers JM. The developmental toxicity of perfluoroalkyl acids and their derivatives. Toxicol Appl Pharmacol. 2004; 198:231-41. [PubMed: 15236955]

12. Olsen GW, Butenhoff JL, Zobel LR. Perfluoroalkyl chemicals and human fetal development: an epidemiologic review with clinical and toxicological perspectives. Reprod Toxicol. 2009; 27:21230. [PubMed: 19429401]

13. Luebker DJ, Case MT, York RG, Moore JA, Hansen KJ, Butenhoff JL. Two-generation reproduction and cross-foster studies of perfluorooctanesulfonate (PFOS) in rats. Toxicology. 2005; 215:126-48. [PubMed: 16146667]

14. Fuentes S, Colomina MT, Vicens P, Domingo JL. Influence of maternal restraint stress on the long-lasting effects induced by prenatal exposure to perfluorooctane sulfonate (PFOS) in mice. Toxicol Lett. 2007; 171:162-70. [PubMed: 17590290] 
15. Butenhoff JL, Kennedy GL Jr, Frame SR, O'Connor JC, York RG. The reproductive toxicology of ammonium perfluorooctanoate (APFO) in the rat. Toxicology. 2004; 196:95-116. [PubMed: 15036760]

16. Apelberg BJ, Witter FR, Herbstman JB, Calafat AM, Halden RU, Needham LL, et al. Cord serum concentrations of perfluorooctane sulfonate (PFOS) and perfluorooctanoate (PFOA) in relation to weight and size at birth. Environ Health Perspect. 2007; 115:1670-6. [PubMed: 18008002]

17. Fei C, McLaughlin JK, Tarone RE, Olsen J. Perfluorinated chemicals and fetal growth: a study within the Danish National Birth Cohort. Environ Health Perspect. 2007; 115:1677-82. [PubMed: 18008003]

18. Fei C, McLaughlin JK, Tarone RE, Olsen J. Fetal growth indicators and perfluorinated chemicals: a study in the Danish National Birth Cohort. Am J Epidemiol. 2008; 168:66-72. [PubMed: 18460444]

19. Washino N, Saijo Y, Sasaki S, Kato S, Ban S, Konishi K, et al. Correlations between prenatal exposure to perfluorinated chemicals and reduced fetal growth. Environ Health Perspect. 2009; 117:660-7. [PubMed: 19440508]

20. Nolan LA, Nolan JM, Shofer FS, Rodway NV, Emmett EA. The relationship between birth weight, gestational age and perfluorooctanoic acid (PFOA)-contaminated public drinking water. Reprod Toxicol. 2009; 27:231-8. [PubMed: 19049861]

21. Stein CR, Savitz DA, Dougan M. Serum levels of perfluorooctanoic acid and perfluorooctane sulfonate and pregnancy outcome. Am J Epidemiol. 2009; 170:837-46. [PubMed: 19692329]

22. Savitz DA, Stein CR, Bartell SM, Elston B, Gong J, Shin HM, et al. Perfluorooctanoic Acid exposure and pregnancy outcome in a highly exposed community. Epidemiology. 2012; 23:38692. [PubMed: 22370857]

23. Fenton SE, Reiner JL, Nakayama SF, Delinsky AD, Stanko JP, Hines EP, et al. Analysis of PFOA in dosed CD-1 mice. Part 2. Disposition of PFOA in tissues and fluids from pregnant and lactating mice and their pups. Reprod Toxicol. 2009; 27:365-72. [PubMed: 19429407]

24. Loccisano AE, Campbell JL Jr, Butenhoff JL, Andersen ME, Clewell HJ 3rd. Evaluation of placental and lactational pharmacokinetics of PFOA and PFOS in the pregnant, lactating, fetal and neonatal rat using a physiologically based pharmacokinetic model. Reprod Toxicol. 2011

25. Fromme H, Mosch C, Morovitz M, Alba-Alejandre I, Boehmer S, Kiranoglu M, et al. Pre-and postnatal exposure to perfluorinated compounds (PFCs). Environ Sci Technol. 2010; 44:7123-9. [PubMed: 20722423]

26. Kim SK, Lee KT, Kang CS, Tao L, Kannan K, Kim KR, et al. Distribution of perfluorochemicals between sera and milk from the same mothers and implications for prenatal and postnatal exposures. Environ Pollut. 2011; 159:169-74. [PubMed: 20932617]

27. Liu J, Li J, Liu Y, Chan HM, Zhao Y, Cai Z, et al. Comparison on gestation and lactation exposure of perfluorinated compounds for newborns. Environ Int. 2011; 37:1206-12. [PubMed: 21620474]

28. Inoue K, Okada F, Ito R, Kato S, Sasaki S, Nakajima S, et al. Perfluorooctane sulfonate (PFOS) and related perfluorinated compounds in human maternal and cord blood samples: assessment of PFOS exposure in a susceptible population during pregnancy. Environ Health Perspect. 2004; 112:1204-7. [PubMed: 15289168]

29. Midasch O, Drexler H, Hart N, Beckmann MW, Angerer J. Transplacental exposure of neonates to perfluorooctanesulfonate and perfluorooctanoate: a pilot study. Int Arch Occup Environ Health. 2007; 80:643-8. [PubMed: 17219182]

30. Monroy R, Morrison K, Teo K, Atkinson S, Kubwabo C, Stewart B, et al. Serum levels of perfluoroalkyl compounds in human maternal and umbilical cord blood samples. Environ Res. 2008; 108:56-62. [PubMed: 18649879]

31. Jensen MS, Norgaard-Pedersen B, Toft G, Hougaard DM, Bonde JP, Cohen A, et al. Phthalates and Perfluorooctanesulfonic Acid in Human Amniotic Fluid: Temporal Trends and Timing of Amniocentesis in Pregnancy. Environ Health Perspect. 2012

32. Kuklenyik Z, Needham LL, Calafat AM. Measurement of 18 perfluorinated organic acids and amides in human serum using on-line solid-phase extraction. Anal Chem. 2005; 77:6085-91. [PubMed: 16159145] 
33. Beesoon S, Webster GM, Shoeib M, Harner T, Benskin JP, Martin JW. Isomer profiles of perfluorochemicals in matched maternal, cord, and house dust samples: manufacturing sources and transplacental transfer. Environ Health Perspect. 2011; 119:1659-64. [PubMed: 21757419]

34. Moore, KL.; Persaud, TVN. The developing human : clinically oriented embryology. 7. Philadelphia, Pa: Saunders; 2003.

35. Luo Z, Shi X, Hu Q, Zhao B, Huang M. Structural Evidence of Perfluorooctane Sulfonate Transport by Human Serum Albumin. Chemical research in toxicology. 2012

36. Kleeberg J, Polishuk WZ. Lipid Determinations in Maternal and Foetal Blood. J Obstet Gynaecol Br Commonw. 1963; 70:701-4. [PubMed: 14078050]

37. Salvalaglio M, Muscionico I, Cavallotti C. Determination of energies and sites of binding of PFOA and PFOS to human serum albumin. J Phys Chem B. 2010; 114:14860-74. [PubMed: 21028884]

38. Harada K, Inoue K, Morikawa A, Yoshinaga T, Saito N, Koizumi A. Renal clearance of perfluorooctane sulfonate and perfluorooctanoate in humans and their species-specific excretion. Environ Res. 2005; 99:253-61. [PubMed: 16194675] 


\section{RESEARCH HIGHLIGHTS}

- Six of eight PFCs tested were detected in maternal prenatal serum; five of eight PFCs tested were detected in amniotic fluid; no PFCs tested were detected in maternal prenatal urine

- PFOA was commonly detected in amniotic fluid if the serum concentration exceeded approximately $1.5 \mathrm{ng} / \mathrm{mL}$

- PFOS was rarely detected in amniotic fluid until the serum concentration was about $5.5 \mathrm{ng} / \mathrm{mL}$ 
Figure 1A.

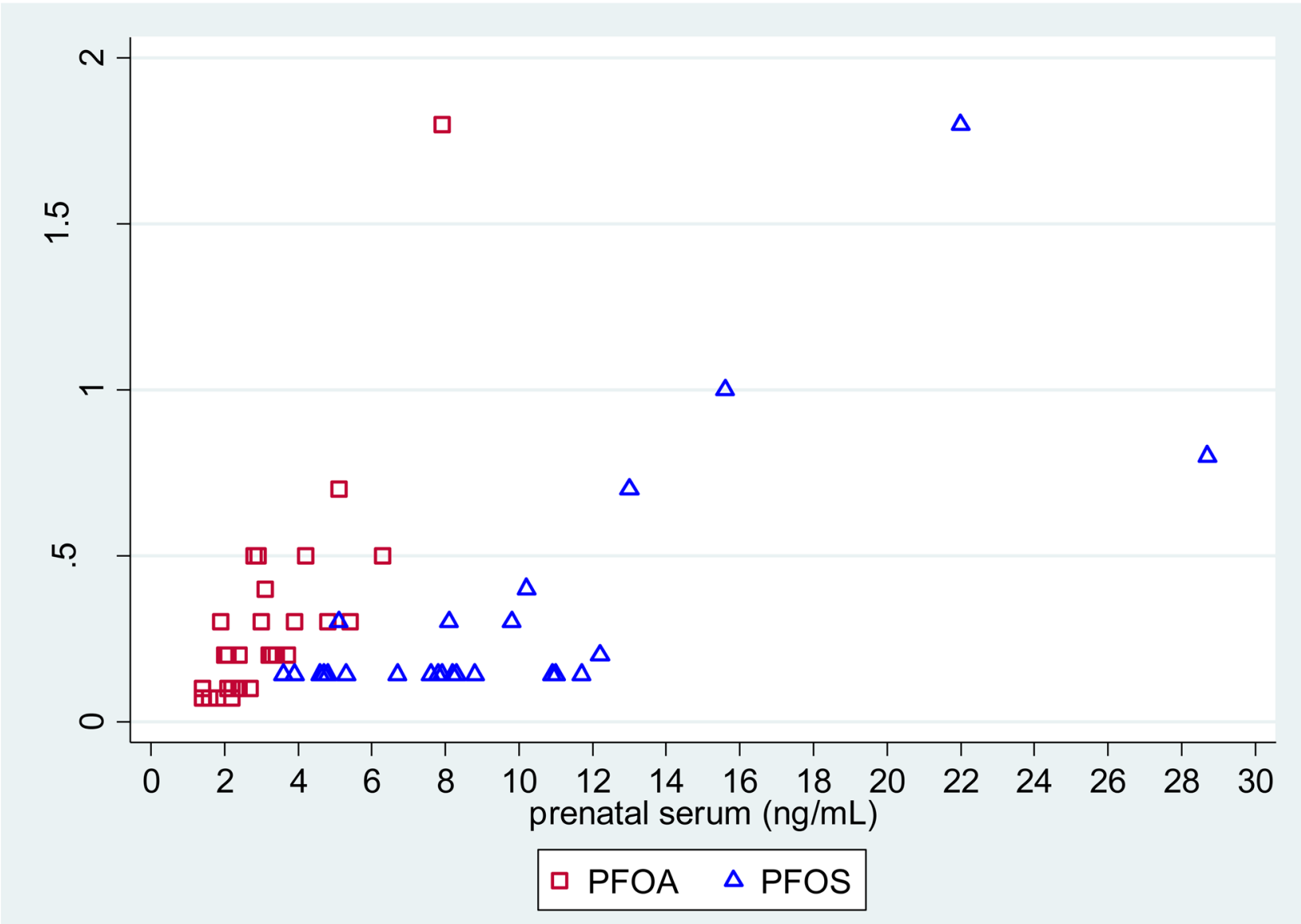

Reprod Toxicol. Author manuscript; available in PMC 2013 November 01. 
Figure 1B.

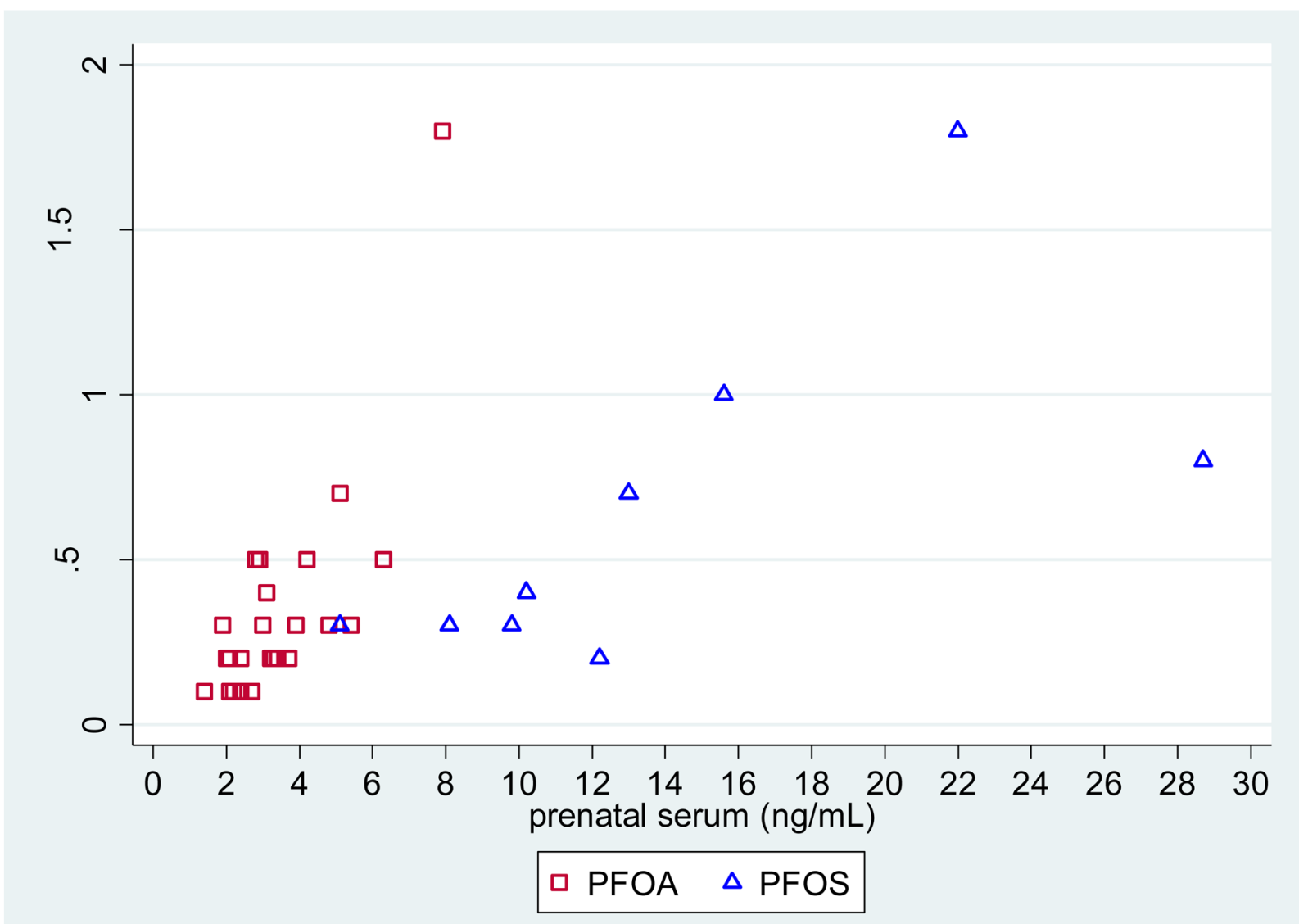

Figure 1.

Figure 1A. Comparison of PFOA and PFOS concentration measured in paired samples of maternal prenatal serum and amniotic fluid, New York, NY, $2005-2008, \mathrm{n}=28$. Amniotic fluid concentrations below the LOD $(0.1 \mathrm{ng} / \mathrm{mL}$, PFOA; $0.2 \mathrm{ng} / \mathrm{mL}$, PFOS $)$ were plotted at the LOD divided by the square root of 2 . PFOA=perfluorooctanoate; PFOS=perfluorooctane sulfonate 2

Figure 1B. Comparison of PFOA and PFOS concentration measured in paired samples of maternal prenatal serum and amniotic fluid, New York, NY, $2005-2008, \mathrm{n}=28$. Amniotic fluid concentrations below the LOD $(0.1 \mathrm{ng} / \mathrm{mL}$, PFOA; $0.2 \mathrm{ng} / \mathrm{mL}$, PFOS $)$ were not plotted. PFOA=perfluorooctanoate; $\mathrm{PFOS}=$ perfluorooctane sulfonate 1.5 
Table 1

Pregnancy Cohort Characteristics, New York, NY, $2005-2008$, n=28

\begin{tabular}{|c|c|c|}
\hline Maternal Characteristics & $\mathbf{N}$ (mean) & Percent (SD) \\
\hline Maternal age at enrollment, years & 33.9 & 5.5 \\
\hline Gestational age at enrollment, weeks & 17.6 & 2.3 \\
\hline Time from amniotic fluid to serum sampling, weeks & 7.9 & 5.9 \\
\hline \multicolumn{3}{|l|}{ Race/ethnicity } \\
\hline Non-Hispanic white & 16 & 57.4 \\
\hline Non-Hispanic black & 5 & 17.9 \\
\hline Hispanic & 4 & 14.3 \\
\hline Asian & 1 & 3.6 \\
\hline American Indian & 2 & 7.1 \\
\hline \multicolumn{3}{|l|}{ Education } \\
\hline High school & 7 & 25.0 \\
\hline College & 10 & 35.7 \\
\hline Graduate school & 11 & 39.3 \\
\hline \multicolumn{3}{|l|}{ Parity } \\
\hline 0 & 1 & 3.9 \\
\hline 1 & 7 & 26.9 \\
\hline $2+$ & 18 & 69.2 \\
\hline \multicolumn{3}{|l|}{ Pre-pregnancy BMI } \\
\hline Underweight & 0 & 0 \\
\hline Normal weight & 15 & 53.6 \\
\hline Overweight & 7 & 25.0 \\
\hline Obese & 6 & 21.4 \\
\hline \multicolumn{3}{|l|}{ Pregnancy weight gain, lbs } \\
\hline $0-25$ & 7 & 25.9 \\
\hline $26-40$ & 10 & 37.0 \\
\hline $41-60$ & 10 & 37.0 \\
\hline
\end{tabular}

Reprod Toxicol. Author manuscript; available in PMC 2013 November 01. 


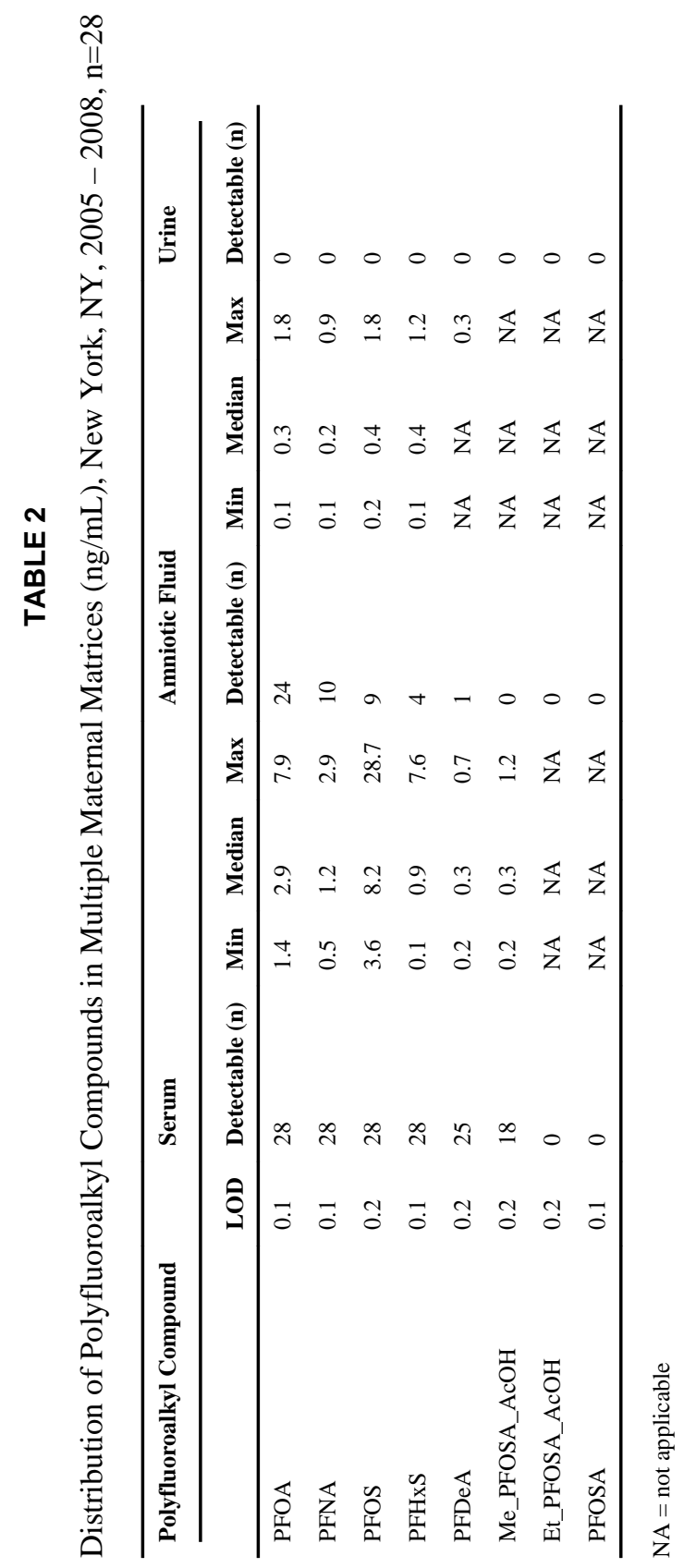

Reprod Toxicol. Author manuscript; available in PMC 2013 November 01. 